\title{
Perception of the influence of cultural diversity on business performance in the automotive component manufacturing in South Africa
}

\begin{tabular}{|c|c|}
\hline \multicolumn{2}{|c|}{$\begin{array}{l}\text { Authors: } \\
\text { Philani M. Khumalo }{ }^{1} \text { (1) } \\
\text { Robert W.D. Zondo }{ }^{1} \text { ( }\end{array}$} \\
\hline \multicolumn{2}{|c|}{$\begin{array}{l}\text { Affiliations: } \\
{ }^{1} \text { Department of } \\
\text { Entrepreneurial Studies and } \\
\text { Management, Faculty of } \\
\text { Management Sciences, } \\
\text { Durban University of } \\
\text { Technology, Durban, } \\
\text { South Africa }\end{array}$} \\
\hline \multicolumn{2}{|c|}{$\begin{array}{l}\text { Corresponding author: } \\
\text { Robert Zondo, } \\
\text { dumisaniz@dut.ac.za }\end{array}$} \\
\hline \multicolumn{2}{|c|}{$\begin{array}{l}\text { Dates: } \\
\text { Received: } 04 \text { Aug. } 2020 \\
\text { Accepted: } 09 \text { Feb. } 2021 \\
\text { Published: } 30 \text { Mar. } 2021\end{array}$} \\
\hline \multicolumn{2}{|c|}{$\begin{array}{l}\text { How to cite this article: } \\
\text { Khumalo, P.M., \& Zondo, } \\
\text { R.W.D. (2021). Perception of } \\
\text { the influence of cultural } \\
\text { diversity on business } \\
\text { performance in the } \\
\text { automotive component } \\
\text { manufacturing in South Africa. } \\
\text { SA Journal of Human Resource } \\
\text { Management/SA Tydskrif vir } \\
\text { Menslikehulpbronbestuur, } \\
\text { 19(0), a1451. https://doi. } \\
\text { org/10.4102/sajhrm. } \\
\text { v19i0.1451 }\end{array}$} \\
\hline \multicolumn{2}{|c|}{$\begin{array}{l}\text { Copyright: } \\
\text { @ 2021. The Authors. } \\
\text { Licensee: AOSIS. This work } \\
\text { is licensed under the } \\
\text { Creative Commons } \\
\text { Attribution License. }\end{array}$} \\
\hline \multicolumn{2}{|l|}{ Read online: } \\
\hline 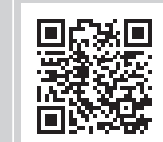 & $\begin{array}{l}\text { Scan this QR } \\
\text { code with your } \\
\text { smart phone or } \\
\text { mobile device } \\
\text { to read online. }\end{array}$ \\
\hline
\end{tabular}

Orientation: Global market demands that organisations remain competitive, flexible and relevant in order to adequately react to culturally diverse changes in their human resources. This sentiment describes the importance of cultural diversity in organisations. However, cultural diversity phenomenon has not been given serious attention by business.

Research purpose: This study examines the perception on the influence of cultural diversity on business performance in automotive component manufacturers in South Africa.

Motivation for the study: Cultural diversity in the organisation has grown over the passage of time with an increase in globalisation. People no longer live in an insular environment. They are part of the worldwide economy competing within a global framework. Hence, cultural diversity becomes a way of creating competitive advantage.

Research design, approach and methods: The study was quantitative in design, with middlelevel managers in two large automotive component manufacturers in the eThekwini District Municipality in KwaZulu-Natal participating in the study. Of the 168 individuals identified for participation, 118 participated in the study, representing a $70.2 \%$ response rate. Descriptive, correlative and $t$-tests, using the Statistical Package for the Social Sciences (SPSS) were used to analyse the data.

Main findings: Study results indicates that a culturally diverse workforce is associated with greater organisational performance, improved strategic decision-making and innovation. Hence, organisations must manage cultural diversity among their workforce for the improvement of business performance.

Managerial implications: Culturally diverse workforce are associated with greater organisational performance, improved strategic decision-making and innovation. Hence, management must develop an understanding of their cultural settings if their organisations are to perform effectively.

Contribution: The original value of this study is its approach in uncovering the strengths and weaknesses of cultural diversity on business performance in South Africa.

Keywords: automotive; business performance; cultural diversity; workgroup; organisational performance; South Africa.

\section{Introduction}

Over the years, cultural diversity has been a subject of great interest to businesses and researchers. As a result of an increase in globalisation, cultural diversity has grown as a trend in organisations (Martin, 2014). This shows that people are part of the worldwide economy competing within a global framework. Martin (2014) added that cultural diversity is present when differences in race, ethnicity, language, nationality, religion and sexual orientation are represented within a community. Mazur (2010) identified geographical location, work experience, income, religious beliefs and marital status as concepts that identify cultural diversity. People's self-image and the way they view the world are shaped by these dimensions (Singh, 2014). Numerous studies (Ehimare \& Ogaga-Oghene, 2011; Martin, 2014; Patrick \& Kumar, 2012; Simons \& Rowlands, 2011) examined the effects of cultural diversity in commerce. However, little research has explored the significance of cultural diversity on business performance. Consequently, this study investigates the influence of cultural diversity on business performance in the automotive industry in South Africa.

Some of the benefits of cultural diversity include creating a competitive advantage, thus increasing work productivity in the organisation (Green et al., 2015). However, Ehimare and Ogaga-Oghene 
(2011) indicated that cultural diversity is associated with creativity and innovation, effective decision-making and greater organisational performance. Mazur (2010) stressed that the increase in cultural diversity increases cognitive bias and social comparisons in the organisation. It results in barriers to social intercourse and could possibly lead to negative performance outcomes for an organisation. Hence, this study examines its influence on business performance in the automotive component manufacturing organisations in South Africa. The study is guided by the following research questions (RQs):

RQ1: Is cultural diversity perceived to have an influence on business performance in the automotive component manufacturing industry in South Africa?

RQ2: What are the opportunities of cultural diversity for business performance in the automotive component manufacturing industry in South Africa?

Changes in the cultural make-up of organisations have made it imperative for managers to understand cultural diversity and how it can affect their respective organisations. Mazur (2010) indicated that cultural diversity can influence businesses in various ways. The positive influences include building a sound knowledge base with in-house talent. This can create a smoother integration of the organisation into foreign cultures. However, negative effects include communication problems, dysfunctional adaptation behaviours and the creation of barriers. When culturally diverse employees are placed in a group to achieve a goal with mutual effort and collaboration, these differences of perceptions and other variables encumber the development of unity (Martin, 2014). Hence, this study explores the influence of cultural diversity on business performance in automotive component manufacturing organisations in South Africa.

The remaining sections of the article consider the literature review, research methodology, results, discussion and the implications of the results for policy and practice, limitations, as well as the conclusion.

\section{Literature review}

This section discusses the overview of culture as a collective programming of the mind, as well as diversity as a variable that influences personal identity. Cultural diversity and business performance conclude the theoretical framework of the study.

\section{Culture as a collective programming of the mind}

Numerous studies (Dike, 2013; Hofhuis, Van der Zee, \& Otten, 2013; Holmgren \& Johnsson, 2013b) presented different definitions of culture (Schnalke \& Mason, 2014), the most common being found in anthropological literature. Mazur (2010) saw culture as a human-made variable, learned and communicated from one generation to another. This is supported by Schnalke and Mason (2014), who stated that cultures are ways of living built up by a group of people and communicated from one generation to another.

Mazur (2010) added that culture is a collective programming of the mind that distinguishes the members of one group or category of people from another. In accordance with Mazur's (2014) definition, Macheo (2016) indicated that culture is a set of collective beliefs, values and norms that distinguish people of a nation from those of another.

It is a multidimensional concept that cannot be dealt with in a single study; it is observed as a concept divided into material and non-material cultures. Sharma (2016) described material culture as physical pieces that are clear and evident, such as clothing, technology, tools and art. However, nonmaterial culture refers to abstract ideas and ways of thinking, languages, morals, norms, attitudes and values admitted and shared in a society. They cannot be seen or touched but can be discovered through the behaviour of individuals.

\section{Diversity as a variable that influences personal identity}

Diversity is defined as a subjective phenomenon, created by members of a group themselves who, based on their different social identities, categorise others as similar or dissimilar (Mazur, 2010).

A group is diverse if it is composed of individuals who differ on a characteristic on which they base their own social identity. This definition is supported by Simons and Rowland (2011) who asserted that diversity distinguishes one group of people from another along primary and secondary dimensions. Primary dimensions exert primary influences on people's identities (Mazur, 2010; Simons \& Rowland, 2011) and include gender, sexual orientation, ethnicity, race, age, mental or physical abilities and characteristics. According to Mazur (2010), primary dimensions shape individuals' selfbase image and their ultimate worldview and have an impact on groups in the society and the workplace. However, secondary dimensions are less noticeable, but exert a more variable influence on personal identity and add a more indirect richness to the primary dimensions of diversity (Mazur, 2010). Secondary dimensions include geographical location, educational background, religion, first language, work style, family status, work experience and income, as well as style of communication (Richard \& Bernett, 2004). Secondary dimensions have an impact on individual's self and self-definition (Simons \& Rowland, 2011).

The position and dominance of each dimension is not fixed, but is more dynamic, thus making the concept of diversity more complex (Martin, 2014). Consequently, secondary dimensions of diversity are more flexible than primary dimensions and change over time. Diversity is neither easy to grasp nor manage. Mazur (2010) emphasised that diversity in the workplace has been associated with multi-cultural, multi-ethnic and multi-racial aspects of the workforce. 
Consequently, Simons and Rowland (2011) defined diversity as any mixture of items characterised by both similarities and differences. In support of this view, Benaglio (2013) proposed that cultural diversity be re-defined as the collective, all-encompassing mix of human differences and similarities along any given dimension. Hence, Martin (2014) concurred that cultural diversity is when differences in race, ethnicity, language, nationality, religion and sexual orientation are represented within an organisation. Singh (2014) indicated that problem-solving in a culturally diverse group provides different perspectives. In a cultural diverse environment, work group increases their effectiveness, thus creating a competitive advantage (Martin, 2014).

\section{Cultural diversity and business performance}

The cultural diversity phenomenon has not been given serious attention by businesses because of a corporate culture that is seemingly characterised by socio-political patronage of people in authority in businesses (Singh, 2014), although indigenous businesses with a global focus are beginning to pay attention to this management challenge.

According to Ehimare and Ogaga-Oghene (2011), little research on the phenomenon of cultural diversity in the African context has been conducted.

Hence, this study assesses cultural diversity in the South African context. Ehimare and Ogaga-Oghene (2011) added that the cultural diversity phenomenon is one of the challenging human resource and organisational issues.

Cultural diversity has been researched in both laboratory and field settings. Laboratory studies, grounded in the valuein-diversity perspective, have indicated that diversity within work groups increases their effectiveness (Sharma, 2016). However, field studies, characterised by social identity and self-categorisation theories, have suggested that cultural diversity is associated with negative performance outcomes. In contrast, Singh (2014) stated that businesses with different levels of cultural diversity experience dissimilar dynamics and organisational outcomes. Within culturally homogeneous groups, members will tend to communicate with one another more often because they shared worldviews and a unified culture, resulting in in-group attachments and shared perceptions (Sharma, 2016). Thus, social identity theory suggests that cultural homogeneity in management groups may increase satisfaction, improve performance and cooperation, and reduce emotional conflict.

Cultural diversity is found to have a contrasting double implication for business performance. Martin (2014) believed that the impact of cultural diversity in the organisation can be both favourable and unfavourable. Some of the negative effects include dysfunctional conflict and lost productivity. However, positive effects comprise of in-house resources of cultural trainers and informers, a strong knowledge base created by an assortment of cultural experiences and a tendency to expand the business in foreign cultures. According to Ehimare and Ogaga-Oghene (2011), cultural diversity is a double-edged sword. It increases the opportunity for creativity, as well as the probability that group members will be dissatisfied and fail to identify with the group. Hence, some studies have found that various forms of diversity are associated with greater organisational performance, improved strategic decision-making and innovation (Martin, 2014).

However, other research shows that various types of organisational diversity increase conflict, reduce social cohesion and increase employee turnover (Mazur, 2010). Richard, Barnett, Dwyer and Chadwick (2004) support Ehimare and Ogaga-Oghene (2011), thus indicating that cultural diversity in organisations has a curvilinear relationship with business performance, in which businesses with low and high levels of homogeneity outperform those with moderate levels of homogeneity.

According to Gómez-mejia and Palich (2016), there are various reasons why global diversification and business performance should positively be related. This view is supported by Kumar (2014) cited in Gómez-mejia et al. (2016), who stated that there is a positive relationship between international diversification and business performance. However, Martin (2014) in Gómez-mejia et al. (2016) reported non-significant or equivocal support for the proposition that business performance is a positive function of international diversification. However, research findings have been contradictory, suggesting that other factors may be responsible for the observed results (Mazur, 2010). Cultural diversity has been widely accepted by businesses as a way of reacting to a competitive edge. The reason for this is that businesses have the opportunity to utilise a vast collection of knowledge, skills and abilities found in a culturally diverse workforce (Stahl, Maznevsk, Viogt, \& Jonsen, 2010). Furthermore, Macheo (2016) and Stahl et al. (2010) stated that all organisations function within a specific culture. It has thus been widely recognised in contemporary discussions of organisational performance that management and other organisational practitioners have to develop an understanding of their cultural setting if their organisations are to perform effectively. Every business organisation's aim is to sustain its existence and meet the needs of its highly competitive market by constantly improving its performance (Arslan \& Staub, 2013).

Organisational performance has been defined as the transformation of inputs into output for achieving certain results. However, Arslan and Staub (2013), cited in Macheo (2016), defined business performance as the execution or accomplishment of work, tasks or goals to a certain level of desired satisfaction. There are various ways to understand business performance. For the purpose of this study, business performance is described as the ability of an organisation or business to satisfy the desired expectations of both owners and customers. Owners' satisfaction is measured with financial returns or profits from organisational operations (Macheo, 2016). 
However, customers' expressed satisfaction is measured by the quality of the products or services of the organisation (Stahl et al., 2010). Mazur (2010) indicated that financial growth of a business is measured through its sales performance. Sales performance refers to economic activities or investments carried out in the organisation within a given period of time. Sales performance is measured by the total amount of income collected for the goods sold. However, employee satisfaction and morale are related to cultural affiliations and identity groups. Factors such as creativity, problem-solving and intra-organisational communication in both formal and informal structures of the organisation are impacted by the degree of diversity (Macheo, 2016). The way people feel and think about their jobs and their employers is influenced greatly by their cultural beliefs, norms and value systems. Mazur (2010) stated that this is essential because behaviour is driven by perceptions of reality. Cox (1994), cited in Macheo (2016), stated that to a great extent, cultural differences shape a person's beliefs and relationship with other employees, as well as with customers.

There is general agreement that proper management of cultural diversity can be an asset to performance (Gómezmejia et al., 2016). However, if it is overlooked or mismanaged, it may diminish the performance of an organisation.

Managing cultural diversity is the action of planning and implementing organisational systems, which includes practices to manage people so that the potential advantages of diversity are maximised, whilst minimising its drawbacks. The goal of cultural diversity management is to maximise the ability of all employees to contribute to organisational goals and to achieve their full potential unhindered by cultural identities such as religion, norms, value systems and language. As culture affects peoples' behaviour, values and customs, people of different cultures work in different ways in business situations (Schnalke \& Mason, 2014). This can be seen through different approaches to punctuality, conflict, structure, different relations to authority and differences in how people see work in relation to their lives (Simons \& Rowland, 2011). Cultural diversity can thus have a significant impact on organisational performance where there is a culturally diverse workforce.

Hofhuis et al. (2013) accentuated that culturally diverse groups work in different ways depending on their cultural diversity. Culturally heterogeneous and culturally homogeneous groups have advantages over one another, in differentcontexts (Holmgren \&Jonsson, 2013b). Homogeneous groups are more effective in situations with a complex context, whereas heterogeneous groups fall short because of perception and attribution differences, as well as communication issues (Macheo, 2016). On the other hand, Holmgren and Jonsson (2013b) advocated that members of heterogeneous groups have different experiences and backgrounds. These groups have the potential to generate more diverse solutions to problems and achieve higher quality results because of greater creativity. Conflicts arise more easily in heterogeneous groups, but they can be more productive and creative in the long run with more generated ideas Simon and Rowland (2011). However, it can be concluded that neither of these groups is superior to the other. Dike (2013) supported this view by indicating that heterogeneous groups tend to be either the most or the least effective teams, whilst homogeneous groups tend to be average. However, it can be assumed that a company could benefit from using both types of groups in different situations to create the highest benefits possible (Sharma, 2016). According to Hofhuis et al. (2013), people often see cultural diversity as something that will not benefit their organisation; yet, it may bring many positive outcomes (Sharma, 2016). Hence, this study examines the perceptions on the influence of cultural diversity on business performance. It explores opportunities of cultural diversity on the performance of the automotive component manufacturers in South Africa.

\section{Methodology}

The methodology covers the target population, sample size, data collection, as well as the measurement and analysis.

\section{Target population}

This study was quantitative in design and carried out in two large automotive component manufacturers operating in the eThekwini District Municipality. Company A had six manufacturing and assembly plants. It employed over 700 people, of whom 91 were middle-level managers. However, Company B had two plants, including the head office. It had a total 603 employees, with 77 middle-level managers.

\section{Sample size}

Of the 168 individuals identified for participation, 118 participated in the study, representing a $70.2 \%$ response rate. In addition, $44.6 \%$ of the participants were white people, $29.5 \%$ were Indians, $14.3 \%$ were mixed race and $11.6 \%$ were Africans.

\section{Data collection}

A self-administered questionnaire was used to collect data. According to Godwill (2015), self-administered questionnaires are useful for collecting data from a large number of participants. The distribution and retrieval of questionnaires were performed from 168 randomly selected middle-level managers. However, a total of 118 questionnaires were returned through the company's human resources managers, representing a $70.2 \%$ response rate, considered high compared with the norm for survey responses (Baruch \& Holtom, 2008). Company A was represented by 67 respondents whilst 51 respondents were from company $\mathrm{B}$.

\section{Measurement and analysis}

The questionnaire was developed from previous research and measured six dimensions on a Likert scale ranging from 
1 (strongly agree) to 5 (strongly disagree). It measured the perception of cultural diversity in the organisation based on the representation in race and culture, as well as organisational performance based on work group problem-solving, work group effectiveness and creating competitive advantage. The measurements considered on the perception of cultural diversity were also used in measuring the opportunities of cultural diversity on business performance. Macheo (2016) defined opportunity as a situation or condition favourable for attainment of a goal.

Hence, the opportunities for cultural diversity include the exchange of creative and innovative ideas, improvement in productivity and profitability and reduction in employee turnover (Sharma, 2016).

The Statistical Package for the Social Sciences (SPSS) version 23.0 was used to do the data analysis. Descriptive, correlation and $t$-tests were used to analyse the data in line with the study objectives.

\section{Study results}

\section{Descriptive analyses on the perception of cultural diversity in business}

Table 1 presents percentage responses on the influence of cultural diversity in business.

Middle managers strongly agreed that cultural diversity had an influence on business in South Africa. Critical factors as presented in Table 1 include critical diversity factors such as the presence of race and different cultures, and the influence is mostly perceived in terms of problem-solving and effectiveness of work groups. The items that received slightly lower scores refer to the broader organisation and specifically organisational performance and competitiveness. However, all the items received mostly positive responses. The results are supported by Ehimare and Ogaga-Oghene (2011) who stated that a culturally diverse workforce is associated with greater organisational performance, improved strategic decision-making and innovation. In addition, Simon and Rowland (2011) asserted that cultural diversity leads to higher flexibility, creativity and ultimately higher effectiveness of the organisation. Furthermore, Green et al. (2015) stated that cultural diversity is a tool that enhances competitive advantage.

\section{A $t$-test on the influence of cultural diversity on business performance}

Four race groups are evident in the study (i.e. Africans, mixed races, Asians and white people), but $t$-tests were conducted to determine differences in mean scores between two groups. The results should indicate whether there are significant differences between the mean scores of two groups. According to Welman, Kruger and Mitchel (2010), $t$-tests determine whether a population mean is significantly different from the hypothesised value. Table 2 presents test results on the influence of cultural diversity on business performance:

1. The test results as shown in Table 2 reveal that there is no statistical significant agreement between race group on the study variables relating to the influence of cultural diversity and business performance at $p$-value of 0.265 $(t[118]=3.969, p>0.05)$, and thus, the hypothesis of no significant agreement between the two variables is acceptable. According to Mazur (2010), racially diverse teams working in relatively homogeneous organisations experienced performance deficits relative to the more homogeneous teams. However, Simon and Rowland (2011) argued that a performance deficit was not evidence for racially diverse teams working in culturally diverse organisations. Furthermore, given the nature of the tasks performed by these teams, in racially homogeneous organisations, the race differences amongst members of diverse teams become more salient and are more likely to interfere with performance (Simon \& Rowland, 2011).

TABLE 2: A t-test on the influence of cultural diversity on business performance. Statistical Influence of cultural diversity Opportunities of cultural diversity technique on business performance on business performance

\begin{tabular}{lcc}
\hline Coefficient & 3.969 & 0.876 \\
df & 117 & 117 \\
Asymp. Sig. & 0.265 & 0.831 \\
\hline
\end{tabular}

Asymp. Sig.

0.265

0.831

Sig. significance; $\mathrm{df}$, degrees of freedom.

TABLE 1: Influence of cultural diversity in business.

\begin{tabular}{|c|c|c|}
\hline Influence of cultural diversity in business & Statements that provide clarity in each factor & $\begin{array}{l}\text { Percentage response accepting } \\
\text { (through a combination of agree and } \\
\text { strongly agree responses) the influence } \\
\text { of cultural diversity in business }\end{array}$ \\
\hline $\begin{array}{l}\text { Cultural diversity is when differences in different } \\
\text { races are represented in the organisation }\end{array}$ & $\begin{array}{l}\text { - Refers to different cultures that respect each other's differences in the organisation. } \\
\text { - Hiring employees from all race groups that creates a diverse workforce. }\end{array}$ & 81.3 \\
\hline $\begin{array}{l}\text { Cultural diversity refers to different cultures } \\
\text { within an organisation }\end{array}$ & $\begin{array}{l}\text { - This refers to cultural variations in the organisation that influence business values, } \\
\text { which in turn affect attitude and, ultimately, behaviour. }\end{array}$ & 94.6 \\
\hline $\begin{array}{l}\text { A culturally diverse workforce is associated } \\
\text { with greater organisational performance }\end{array}$ & $\begin{array}{l}\text { - Cultural diversity correlates with the improvement in productivity and profitability. } \\
\text { - Multicultural workforce results in the expansion of the existing and new markets } \\
\text { and develops collaboration regardless of the business model. }\end{array}$ & 74.1 \\
\hline $\begin{array}{l}\text { Problem-solving in a culturally diverse group } \\
\text { will provide different perspectives }\end{array}$ & $\begin{array}{l}\text { - Organisations achieve better results from diverse groups of employees with different } \\
\text { backgrounds that possess a variety of skills. } \\
\text { - This also refers to differences in perspectives and methods of approaching problems } \\
\text { that most often lead to better outcomes. }\end{array}$ & 93.8 \\
\hline $\begin{array}{l}\text { Cultural diversity within a work group } \\
\text { increases their effectiveness }\end{array}$ & $\begin{array}{l}\text { - Cultural diversity inspires creativity and drives innovation. } \\
\text { - Culturally diverse work teams are more productive and perform better. }\end{array}$ & 80.3 \\
\hline $\begin{array}{l}\text { Cultural diversity is a way of creating } \\
\text { competitive advantage }\end{array}$ & $\begin{array}{l}\text { - Cultural diversity can expand the range of available ideas on which the company } \\
\text { can capitalise. } \\
\text { - It better the company in a better way to meet the needs of a diverse global } \\
\text { marketplace. }\end{array}$ & 75.9 \\
\hline
\end{tabular}


TABLE 3: Spearman's correlation test on the influence of cultural diversity on business performance.

\begin{tabular}{llcc}
\hline Statistical technique & & $\begin{array}{c}\text { Influence of } \\
\text { cultural diversity } \\
\text { on business } \\
\text { performance }\end{array}$ & $\begin{array}{c}\text { Opportunities of } \\
\text { cultural diversity } \\
\text { on business } \\
\text { performance }\end{array}$ \\
\hline Spearman's rho & Correlation Coefficient & 1.000 & $0.383^{* *}$ \\
$\begin{array}{l}\text { Influence of cultural } \\
\text { diversity on business } \\
\text { performance }\end{array}$ & Sig. (2-tailed) & 0.000 & 0.000 \\
$\begin{array}{llll}\text { Opportunities of } \\
\text { cultural diversity }\end{array}$ & Correlation Coefficient & 118 & 118 \\
on business & Sig. (2-tailed) & $0.383^{* *}$ & 1.000 \\
performance & $N$ & 0.000 & 0.000 \\
\hline
\end{tabular}

Sig., significance.

**, Correlation is significant at the 0.01 level (2-tailed).

2. Table 2 determines the significant agreement on the study variables relating to the opportunities of cultural diversity. The study reveals that there is no statistically significant agreement between race groups on the study variables relating to the opportunities of cultural diversity and business performance at $p$-value of $0.831(t[118]=0.876$, $p>0.05)$, and thus, the hypothesis of no significant agreement between the two variables is acceptable. The results are supported by Mazur (2010) who indicated that a racially diverse workforce is associated with greater organisational performance, improved strategic decisionmaking and innovation.

\section{Correlation test on the influence of cultural diversity on business performance}

The Spearman's Rho correlation analysis (Table 3) was also used to test the relationship between the influence of cultural diversity on business performance and the opportunities of cultural diversity on business performance. These tests measure the statistical relationship, or association, between two continuous variables (Welman, Kruger, \& Mitchell, 2010).

Test results in Table 3 on the influence of cultural diversity on business performance and opportunities of cultural diversity on business performance show a coefficient $r$-value of 0.383 .

This indicates a directly proportional relationship between the two variables. This finding is supported by Martin (2014) who indicated that cultural diversity is associated with greater organisational performance, improved strategic decisionmaking and innovation. The goal of cultural diversity is to maximise the ability of all employees to contribute to organisational goals and achieve their full potential unhindered, by cultural identities such as religion, norms, value systems and language (Schnalke \& Mason, 2014).

\section{Discussion}

The study investigates the influence of cultural diversity on business performance in the automotive components manufacturing industry in South Africa. It examined the opportunities of cultural diversity on business performance, using descriptive and $t$-tests to analyse data. The study indicates that a culturally diverse workforce is associated with greater organisational performance. Cultural diversity within a work team increases their effectiveness. This is confirmed by Ehimare and Ogaga-Oghene (2011) who indicated that a culturally diverse workforce is associated with greater organisational performance, improved strategic decisionmaking and innovation. Simon and Rowland (2011) added that cultural diversity may lead to higher flexibility, creativity and ultimately higher effectiveness of the organisation.

\section{Implications of results for policy and practice}

It is essential that management and other organisational practitioners develop an understanding of their cultural settings if their organisations are to perform effectively (Macheo, 2016). This must be based on an understanding of the economic factors affecting cultural diversity on business performance (Stahl et al., 2010). Besides the achievements of study objectives, organisations should consider the following practices:

1. A culturally diverse workforce must be associated with greater organisational performance, improved strategic decision-making and innovation (Ehimare \& OgagaOghene, 2011).

2. Cultural diversity within a work group should be able to increase business effectiveness (Simon \& Rowland, 2011).

\section{Study limitations}

The study provided with a series of theoretical observations that pertain to the entire world and not specifically to South Africa. Such data were broader in their general application. However, the investigation on the perceptions of cultural diversity on business performance was limited in two automotive component manufacturing organisations that operate within the eThekwini District Municipality. As there are 22 registered automotive plants in South Africa (SAinfo, 2018), the results cannot be extrapolated to other companies within the sector.

\section{Conclusion}

A culturally diverse workforce is a true reflection of a changing world and marketplace (Mazur, 2010). Given the importance of business performance in most economies, this study provided important practical implications for management's decision-making and policy. Hence, Benaglio (2013) proposed that diversity be re-defined as the collective, all-encompassing mix of human differences and similarities along any given dimension. Thus, cultural diversity must be associated with creativity and innovation, effective decisionmaking and greater organisational performance (Ehimare \& Ogaga-Oghene, 2011).

\section{Acknowledgements Competing interests}

The authors declare that they have no financial or personal relationships that may have inappropriately influenced them in writing this article. 


\section{Authors' contributions}

R.W.Z. was the project leader. P.M.K. initiated the project, collected theoretical and raw data, and analysed the data. R.W.Z. prepared and compiled the manuscript to an acceptable level.

\section{Funding information}

This research received no specific grant from any funding agency in the public, commercial, or not-for-profit sectors.

\section{Ethical considerations}

The researchers complied with the following: the process for the collection of data did not involve access to confidential personal data; the research fulfils the criteria for informed consent; respondents were not asked to perform any acts or make statements, which might be expected to cause discomfort; researcher did not expect to obtain any direct or indirect financial or other benefits from conducting the research.

\section{Data availability}

Data sharing is not applicable to this article as no new data were created or analysed in this study.

\section{Disclaimer}

The views and opinions expressed in this article are those of the authors and do not necessarily reflect the official policy or position of any affiliated agency of the authors.

\section{References}

Arslan, A., \& Staub, S. (2013). Theory $X$ and theory $Y$ type leadership behavior and its impact on organisational performance: Small business owners in the Şishane Lighting and Chandelier District. Journal of Social and Behavioral Science, 75 102-111. https://doi.org/10.1016/j.sbspro.2013.04.012

Baruch, Y., \& Holtom, B.C. (2008). Survey response rate levels and trends in organisational research. Human Relations, 61(8), 1139-1160. https://doi. org/10.1177/0018726708094863 Cox, T. (1994). Cultural Diversity in Organizations: Theory, Research and Practice. San
Francisco: Berett-Koehler.
Dike, P. (2013). The impact of workplace diversity on organisations. Diversity Management, 2(3), 1-59.

Ehimare, O.A., \& Ogaga-Oghene, J.O. (2011). The impact of workforce diversity on organisational effectiveness: A study of a Nigerian Bank. Annals of the University Petrosani, Economics, 11(3), 93-110.

Gómez-mejia, L.R., \& Palich, L. (2016). Cultural diversity and the performance of multinational firms. Journal of International Business Studies, 28(2), 309-335. https://doi.org/10.1057/palgrave.jibs.8490103

Green, K., Lopez, M., Wysocki, A., Kepner, K., Farnsworth, D., \& Clark, J. (2015). Diversity in the workplace: Benefits, challenges and the required managerial tools. Journal of Food and Resource Economics 2-3.

Hofhuis, J., Van der Zee, K., \& Otten, S. (2013). Measuring employee's perception on the effects of cultural diversity at work: Development of the benefits and threats of diversity scale. Quality \& Quantity, 49(3), 177-201. https://doi.org/10.1007/ s11135-013-9981-7

Holmgren, D., \& Jonsson, A. (2013a). Cultural diversity in organisations: A study on the view and management on cultural diversity. Business Administration, 2, 85-100.

Holmgren, K., \& Jonsson, R. (2013b). Does unbalanced gender composition in the workplace influence the association between psychosocial working conditions and sickness absence? Work, 46(1), 59-66. https://doi.org/10.3233/WOR-121529

Krishna, G. (2017). Managing cross-cultural issues in global software development. Communications of the ACM, 47(4), 62-66.

Kumar, R. (2014). Research methodology: A step by step for beginners (4th edn.). London: Sage.

Luis, G., \& Palich, L. (2016). Cultural diversity and the performance of multinational firms. Journal of international business studies, 28(2), 309-335.

Macheo, K. (2016). The effects of cultural diversity on organisational performance. NJ: Beverly.

Martin, G.C. (2014). The effects of cultural diversity in the workplace. Journal of Diversity Management, 9(2), 89-92. https://doi.org/10.19030/jdm.v9i2.8974

Mazur, B. (2010). Cultural diversity in organisational theory and practice. Journal of Intercultural Management, 2(2), 5-15.

Patrick, H.A., \& Kumar, V.R. (2012). Managing workforce diversity: Issues and challenges. Sage Open, 2(2), 1-15. https://doi.org/10.1177/2158244012444615

Richard, O., Barnett, T., Dwyer, S., \& Chardwick, K. (2004). Cultural diversity in management, firm's performance, and the moderating role of entrepreneurial orientation dimensions. Academy of management journal, 47(2): 255-266. https://doi.org/10.5465/20159576

SAinfo. (2008). South Africa's automotive industry, Retrieve from http://www. southafrica.info/doing_business/economy/key_sectors/motorindustryboost. html

Schnalke, M., \& Mason, R. (2014). The influence of culture on marketing communications: Critical culture factors influencing South African and German businesses. Problems and Perspectives in Management, 12(1), 172-180.

Simons, N., \& Rowland, K. (2011). Doversity and its impact on organiszational performance: The influence of diversity constructions on expectations and outcomes. Journal of Technology Management and Innovation, 6(3), 172-183. https://doi.org/10.4067/S0718-27242011000300013

Singh, D. (2014). Managing cross-cultural diversity: Issues and challenges in global organisations. Journal of Mechanical and Civil Engineering, 3, 43-50.

Stahl, G., Maznevski, M., Viogt, A., \& Jonsen, K. (2010). Unraveling the effects of cultural diversity in teams: A meta-analysis of research on multicultural work groups. Journal of International Business Studies, 41(4), 690-709. https://doi. org/10.1057/jibs.2009.85

Welman, C., Kruger, F., \& Mitchell, B. (2010). Research methodology (8th edn.). Cape Town: Oxford University Press. 